\title{
Descrição de uma nova espécie de Thamnodynastes Wagler, 1830 (Serpentes, Colubridae) do nordeste brasileiro, com comentários sobre o gênero
}

\section{Francisco L. Franco e Talita Gancev Ferreira}

Laboratório de Herpetologia, Instituto Butantan, Av. Vital Brazil, 1500, CEP 05503-900, São Paulo, SP, Brasil. Email: flfranco@butantan.gov.br.

\begin{abstract}
Description of a new species of Thamnodynastes Wagler, 1830 (Serpentes, Colubridae) from northeastern Brazil, with comments on the genus. Thamnodynastes almae sp. nov. is described based on three specimens from Rodelas Municipality, state of Bahia, Northeastern Brazil. The new species can be diagnosed by its pale coloration and keeled dorsal scales arranged in 19 rows at midbody and 15 rows posteriorly. Characters for distinguishing T. almae from other Brazilian species of Thamnodynastes are provided.
\end{abstract}

Keywords: Thamnodynastes almae sp. nov., Thamnodynastes, Colubridae, Xenodontinae, Caatingas, Northeastern Brazil.

Palavras-Chave: Thamnodynastes almae sp. nov., Thamnodynastes, Colubridae, Xenodontinae, Caatingas, nordeste do Brasil.

\section{Introdução}

As serpentes do gênero Thamnodynastes Wagler, 1830 são colubrídeos pertencentes à subfamília Xenodontinae Bonaparte 1845, que apresenta muitos problemas taxonômicos, incluindo seu monofiletismo. Os Xenodontinae ocorrem em todo o continente americano sendo especialmente diversificados na América do Sul (Cadle 1984a, 1985, 1987, Cadle e Greene 1993, Zaher 1999). Das 294 espécies de serpentes registradas para o Brasil, 149 (cerca de 50\%)

Recebido em 13 de dezembro de 2002

Aceito em 29 de dezembro de 2002 pertencem a essa subfamília. Há várias propostas de classificação e composição dessa subfamília (Dunn 1928, Dowling e Duellman 1978, Jenner 1981, Dowling et al. 1983, Cadle 1984a, b, 1985, Cadle e Dessauer 1985, Jenner e Dowling 1985, Dessauer et al. 1987, McDowell 1987, Ferrarezzi 1994, Zaher 1999). Os Xenodontinae lato sensu são divididos em três linhagens: os xenodontíneos norteamericanos, os centroamericanos e os sulamericanos (Dowling e Duellman 1978, Cadle 1984a, b, Dowling et al. 1983, Cadle e Dessauer 1985, Jenner e Dowling 1985, Dessauer et al. 1987). Alguns autores consideram os xenodontíneos centroamericanos como um grupo com status de subfamília, Dipsadinae 
Bonaparte, 1838 (Dowling et al. 1983, Jenner e Dowling 1985, Zaher 1999), enquanto outros consideram-nos como uma tribo (Dipsadini) da subfamília Xenodontinae (Dowling e Duellman 1978, McDowell 1987, Ferrarezzi 1994). Os resultados obtidos por Vidal et al. (2000) mostraram que os xenodontíneos sulamericanos e centroamericanos são grupos-irmãos, sendo coerente com o status taxonômico de subfamília, como assumido por Zaher (1999) e seguido neste trabalho.

Bailey (1966, 1967b) propôs a tribo Tachymenini Bailey, 1967 como sendo composta pelos gêneros Tomodon Duméril, 1853, Ptychophis Gomes, 1915, Tachymenis Wiegmann, 1834, Thamnodynastes Wagler, 1830, Gomesophis Hoge e Mertens, 1959, Pseudotomodon Koslowsky, 1896 e, provavelmente, Calamodontophis Amaral, 1963. Embora o monofiletismo de Tachymenini não tenha sido aceito por diversos autores (Underwood 1967, Dowling e Duellman 1978, Jenner e Dowling 1985, Zaher 1999), uma série de caracteres (Bailey 1966, 1967a, b, 1981, Beçak e Beçak 1969, Cadle 1984a, Shine 1985, Ferrarezzi 1994), sintetizados em Franco (1999), sugerem um relacionamento filogenético próximo entre os gêneros acima citados, corroborando a proposta de Bailey (1966, 1967b).

Zaher (1999) restrigiu o contexto da subfamília Xenodontinae, excluindo vários táxons. Contudo, essa proposta é dúbia quanto à classificação dos gêneros de Tachymenini. Zaher (1999) citou os gêneros considerados como Tachymenini em "Xenodontines incertae sedis”, enquanto, na tabela de seu Appendix I, os mesmos estão citados como Dipsadinae incertae sedis. Segundo Zaher (1999), o hemipênis das serpentes desses gêneros seguem o padrão de Dipsadinae e, por esse motivo, são colocados em incertae sedis. Zaher (1999) não especificou se considera esses gêneros como Colubridae incertae sedis, ou seja, não propôs a alocação destes ao nível de subfamília, ou se os considera como Xenodontinae ou Dipsadinae incertae sedis, isto é, não sugeriu a alocação tribal dos mesmos dentro de uma dessas subfamílias. Como o objetivo de Zaher (1999) foi o de reduzir a subfamília Xenodontinae a um grupo menor e monofilético, é de se supor que seu intuito tenha sido o de retirar esses gêneros incluídos em Tachymenini, entre outros, do contexto de Xenodontinae. Além disso, como Zaher (1999) considerou o hemipênis dos Tachymenini dentro do padrão de Dipsadinae e fragilizou as hipóteses de monofiletismo da tribo Tachymenini, pode-se concluir que seu objetivo era o de considerar os gêneros dessa tribo como Dipsadinae incertae sedis, como visto na tabela de seu Appendix I. Vidal et al. (2000) apresentaram evidências de que Thamnodynastes (um Tachymenini) está intimamente relacionado com outros gêneros reconhecidamente xenodontíneos (e.g. Liophis, Oxyrhopus, Philodryas, Xenodon). Desse modo, até que novos trabalhos mais conclusivos venham a alterar as propostas tradicionais, optou-se por considerar a tribo Tachymenini como integrante da subfamília Xenodontinae.

O gênero Thamnodynastes é composto atualmente por 11 espécies. São serpentes pequenas, vivíparas e opistóglifas, com pupila vertical elíptica, que ocupam ampla variedade de hábitats e ambientes (Bailey 1967b, Franco 1999). Os representantes do gênero distribuemse por grande parte da América do Sul, desde aproximadamente $10^{\circ} \mathrm{N}$, na Colômbia (PérezSantos e Moreno 1989), até $37^{\circ} \mathrm{S}$, na Argentina (Bellagamba e Vega 1996). A literatura taxonômica do gênero é caótica, mesmo após as recentes contribuições. Desde 1989, diversos autores propuseram independentemente uma sinonimização, uma revalidação e a descrição de seis espécies novas, sendo elas: Thamnodynastes gambotensis Pérez-Santos e Moreno, 1989, a revalidação de Thamnodynastes hypoconia (Cope, 1860) e a sinonimização de Thamnodynastes strigilis (Thunberg, 1787) com Thamnodynastes pallidus (Linnaeus, 1758) por Cei et al. (1992), Thamnodynastes chaquensis Bergna e Alvarez, 1993, Thamnodynastes duida Myers e Donnelly, 1996, Thamnodynastes yavi 
Myers e Donnelly, 1996, Thamnodynastes corocoroensis Gorzula e Ayarzagüena, 1996 e Thamnodynastes marahuaquensis Gorzula e Ayarzagüena, 1996. Além disso, ainda há muitas espécies não descritas sendo estudadas por R. A. Thomas (Loyola University, Lousiana) e J. Bailey (in memorian) (R. A. Thomas, com. pess.) e pelos autores deste artigo.

Segundo Peters e Orejas-Miranda (1970), Franco (1999) e Marques et al. (2001), são registradas quatro espécies de Thamnodynastes para o território brasileiro, Thamnodynastes rutilus (Prado, 1942), Thamnodynastes strigatus (Günther, 1858), T. pallidus e T. hypoconia. Todas essas espécies ocorrem no Domínio Tropical Atlântico (Ab’Saber 1977), sendo também encontradas em outras formações morfoclimáticas e fitogeográficas.

A análise de exemplares do gênero Thamnodynastes revelou a existência de algumas espécies não descritas ou por revalidar, uma das quais está sendo descrita neste trabalho. Adicionalmente, registrou-se a ocorrência de $T$. chaquensis no território brasileiro.

\section{Material e Métodos}

Foram examinados exemplares provenientes das seguintes coleções, cujos acrônimos seguem a indicação da própria instituição (Apêndice I): Coleção Herpetológica “Alphonse Richard Hoge” (IB), do Laboratório de Herpetologia do Instituto Butantan, São Paulo, SP. Coleção Paralela do Instituto Butantan (CP), material a ser incorporado na coleção principal. Coleção Herpetológica da Seção de Herpetologia do Museu Nacional (MNRJ), Universidade Federal do Rio de Janeiro, Rio de Janeiro, RJ.

Foram analisados os seguintes caracteres da morfologia externa: o padrão de desenho e colorido, a forma geral do corpo, cabeça e cauda, escutelação cefálica, presença, número e relações entre escamas e placas, contagens de escamas (dados merísticos), tomada de medidas (dados morfométricos). Esses caracteres foram observados a olho nu ou com o auxílio de mi- croscópio estereoscópico. A terminologia utilizada e a padronização da obtenção de dados seguem as propostas de Dowling (1951) e Peters (1964).

Abreviaturas usadas no texto e tabelas: Ccab: comprimento da cabeça. Ccau: comprimento da cauda. CRC: comprimento rostrocloacal. Des.: desenhos e pigmentação. DO: número de fileiras de escamas dorsais a uma cabeça de distância da cabeça, no meio corpo e a uma cabeça de distância da cauda, apresentados nessa ordem, separados por barras (/). DP: desvio padrão. E: região anterior do ventre mais clara que posterior. H: tonalidade da região anterior do ventre semelhante à posterior. IL: número de escudos infralabiais (entre parênteses, número de IL em contato com mentonianas). L: linhas longitudinais no ventre. M: ventre mesclado ou xadrez. N: número de exemplares examinados. P: ventre com pigmentos escuros. SC: número de pares de escamas subcaudais. SL: número de escudos supralabiais (entre parênteses, número de SL em contato com o globo ocular). Temp.: escudos temporais (primários + secundários). X: média aritmética. VE: número de escamas ventrais.

\section{Thamnodynastes Wagler, 1830}

1830 Thamnodynastes Wagler, Nat. Syst. Amphib., 182. Espécie-tipo: Natrix punctatissimus Wagler, 1824, in Spix, Sp. Nov. Serp. Bras.: 39.

1830 Dryophylax Wagler, Nat. Syst. Amphib., 181. Espécie-tipo: Coluber nattereri Mikan, 1828.

1863 Mesotes Jan, Arch. Zool. Anat. Fis., 2: 306. Espécie-tipo: Mesotes obtrusus Jan, 1863.

Componentes: Thamnodynastes chaquensis Bergna e Alvarez, 1993, T. chimanta Roze, 1958, T. corocoroensis Gorzula e Ayarzagüena, 1996, T. duida Myers e Donnelly, 1996, T. gambotensis Pérez-Santos e Moreno, 1989, T. hypoconia (Cope, 1860), T. marahuaquensis 
Gorzula e Ayarzagüena, 1996, T. pallidus (Linnaeus, 1758), T. rutilus (Prado, 1942), T. strigatus (Günther, 1858) e T. yavi Myers e Donnelly, 1996, além da espécie descrita no presente trabalho.

As serpentes do gênero Thamnodynastes são vivíparas, opistóglifas, com olhos com pupila vertical elíptica, de porte pequeno a médio, escudo nasal simples ou semidividido e com desenho dorsal com padrão xadrez na região anterior e variegado ou com linhas longitudinais laterais na região posterior. Ventralmente, as espécies apresentam linhas longitudinais (duas a sete, normalmente quatro) mais ou menos nítidas, às vezes perdidas ( $T$. corocoroensis) ou alteradas (Thamnodynstes sp. 5), porém derivadas do padrão lineado.

Os hemipênis das espécies de Thamnodynastes apresentam o padrão básico dos Tachymenini (Zaher 1999). O ápice é coberto com cálices bem-definidos, geralmente levemente bilobados, unicaliculado e não-capitado, com sulco espermático bifurcado apicalmente, centrolinear, dentro da região caliculada; normalmente, o corpo do hemipênis é recoberto por espinhos pequenos não-diferenciados, que podem aumentar de tamanho à medida que se aproximam da base, podendo ou não apresentar ganchos basais (Zaher 1999). Em T. yavi, o hemipênis é simples (Myers e Donnelly 1996) e, em $T$. hypoconia, delgado, com sulco espermático bifurcado muito apicalmente, aparentando ser simples (Cei et al. 1992).

Distribuem-se por grande parte da América do Sul, desde aproximadamente $10^{\circ} \mathrm{N}$, na Colômbia (Pérez-Santos e Moreno 1989) até $37^{\circ} \mathrm{S}$, na Argentina (Bellagamba e Vega 1996).

Thamnodynastes almae sp. nov.

(Figuras 1, 2 e 4, Tabelas 1 e 2)

Holótipo (Figuras 1 e 2, Tabela 1): IB 52135 exemplar macho, adulto. Coletado na Usina Hidroelétrica Luiz Gonzaga (entre 090 06'
$\mathrm{S}-38^{\circ} 20^{\prime} \mathrm{W}, 280 \mathrm{~m}$ e $08^{\circ} 51^{\prime} \mathrm{S}-38^{\circ} 45^{\prime} \mathrm{W}$, $300 \mathrm{~m}$ ), no rio São Francisco, município de Rodelas, estado da Bahia, Brasil, entregue ao Laboratório de Herpetologia do Instituto Butantan em 20 de abril de 1988 pela equipe de resgate de fauna da Companhia Hidroelétrica do São Francisco (CHESF).

Parátipos (Tabela 1): IB 52134, fêmea jovem, e IB 52136, fêmea adulta, sem crânio, ambos procedentes da Usina Hidroelétrica Luiz Gonzaga (entre 0906's - 38 $20^{\circ} \mathrm{W}, 280 \mathrm{~m}$ e 0851'S - 3845’W, $300 \mathrm{~m})$, município de Rodelas, BA, entregues ao Laboratório de Herpetologia do Instituto Butantan em 20 de abril de 1988 pela equipe de resgate de fauna da CHESF.

Distribuição geográfica (Figura 4): Thamnodynastes almae sp. nov. é conhecida apenas da localidade-tipo. Não foi possível determinar a localidade de forma mais precisa, decidindo-se, portanto, manter o município de Rodelas (BA) como localidade-tipo devido à sua grande extensão nas margens da referida represa. A área da represa está contida no Domínio das Caatingas (Ab’Saber 1974, 1977).

Diagnose (Tabelas 2 e 3): Thamnodynastes almae sp. nov. é uma espécie de grande porte em relação às demais espécies do gênero (CRC, $X=509 \mathrm{~mm}, \mathrm{DP}=205,00, \mathrm{~N}=3$; Ccau, $\mathrm{X}=$ $143,3, \mathrm{DP}=60,28, \mathrm{~N}=3$, maior exemplar, IB 52135, macho, CRC de $657 \mathrm{~mm}$ e Ccau de 189 $\mathrm{mm}$ ), semelhante ao porte de T. strigatus (CRC, $\mathrm{X}=454,8 \mathrm{~mm}, \mathrm{DP}=115,27, \mathrm{~N}=44$; Ccau, $\mathrm{X}$ $=126 \mathrm{~mm}, \mathrm{DP}=37,24, \mathrm{~N}=45$, maior exemplar, IB 9721, macho, CRC de $715 \mathrm{~mm}$, Ccau de $212 \mathrm{~mm}$ ). Possui coloração clara, marromclaro amarelado. Distingüe-se das demais espécies de Thamnodynastes com 19 fileiras de escamas no meio do corpo - Thamnodynastes sp. 4, T. gambotensis, T. rutilus, T. strigatus e T. yavi - pois estas apresentam escamas dorsais lisas enquanto T. almae sp. nov. apresenta escamas quilhadas. Distingüe-se de T. chaquensis e $T$. hypoconia por estas apresentarem regiões 

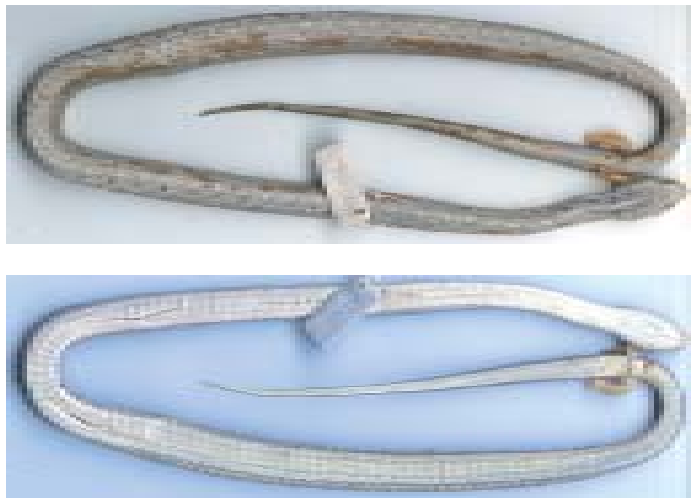

Figura 1 - Thamnodynastes almae sp. nov. (Holótipo, IB 52135). A) vista dorsal, B) vista ventral.
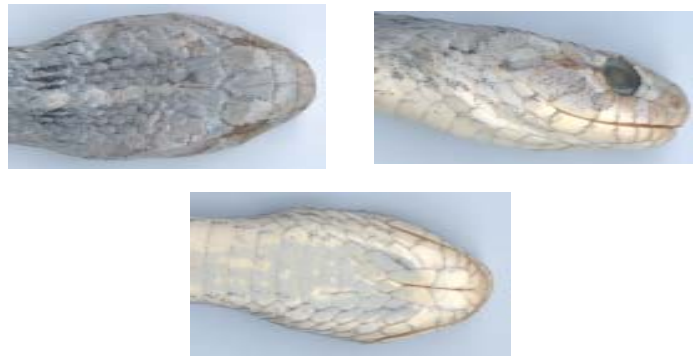

Figura 2 - Cabeça de Thamnodynastes almae sp. nov. (Holótipo, IB 52135). A) vista dorsal, B) vista lateral direita, C) vista ventral.
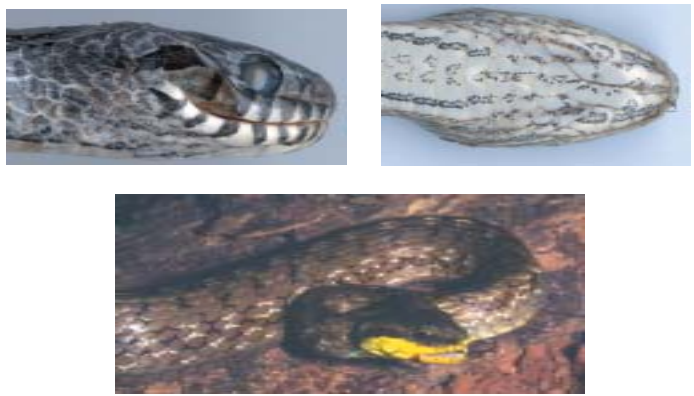

Figura 3 - Detalhes da cabeça de Thamnodynastes spp. (A) Thamnodynastes strigatus (IB 64113), vista lateral direita; (B) Thamnodynastes hypoconia (IB 54020), vista ventral; (C) Thamnodynastes rutilus, exemplar adulto, Presidente Epitácio, SP (Rio do Peixe). (Foto Rogério Bertani.) gular e mentoniana com manchas, enquanto $T$. almae sp. nov. apresenta região gular imaculada (Figura 2C). Distingüe-se de Thamnodynastes sp. 1 pelo dorso mais escuro e o ventre lineado, que escurece gradativamente em direção à cloaca; T. almae sp. nov. é extremamente clara, com ventre lineado homogêneo, que não escurece em direção à cloaca (Figura $1 \mathrm{~B})$. Distingüese de Thamnodynastes sp. 2, pois esta apresenta regiões mentoniana e gular com manchas escuras e escamas subcaudais em número igual ou maior a 59 (SC, $X=50,2, D P=3,86, N=14$ ), enquanto $T$. almae sp. nov. apresenta regiões gular e mentoniana imaculadas (Figura 2C) e escamas subcaudais em número igual ou inferior a 57 (SC, $\mathrm{X}=62,6, \mathrm{DP}=3,51, \mathrm{~N}=3$ ) (Tabela 2).

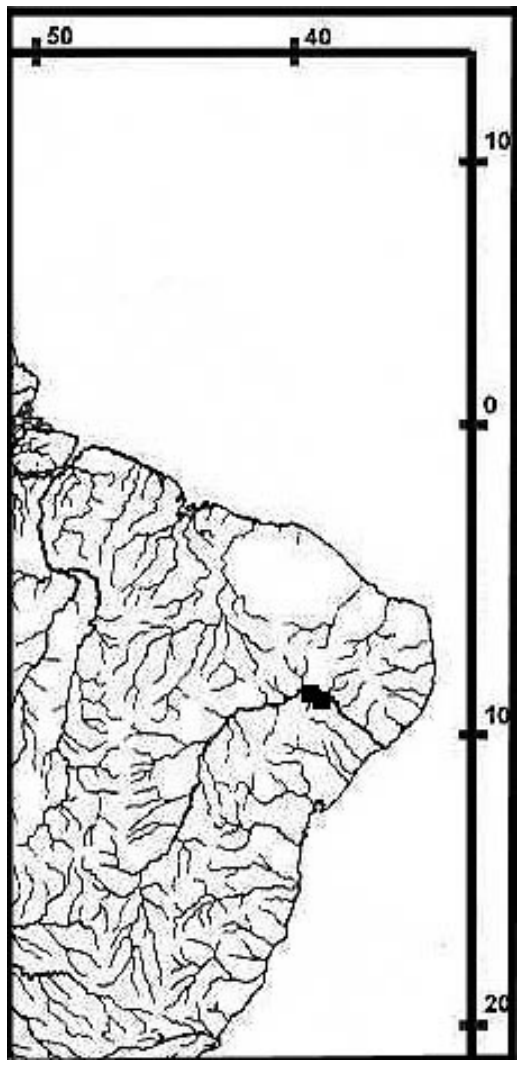

Figura 4 - Distribuição geográfica dos exemplares examinados de Thamnodynastes almae sp. nov. 
Descrição do holótipo (Figuras 1 e 2, Tabela 1): IB 52135. Exemplar macho, adulto, com hemipênis esquerdo evertido e direito parcialmente evertido, com CRC de $657 \mathrm{~mm}$, Ccau de 189 mm e Ccab de 30,4 mm (Tabela 1). Serpente de porte médio, com cabeça destacada do corpo e cauda perfazendo $22,3 \%$ do comprimento total.

Dorsalmente, a cabeça apresenta o padrão de escutelação típica dos demais colubrídeos (Figura 2A). Escudo rostral pouco visível dorsalmente. Escudos supralabiais 8/8, $4^{\circ}$ e $5^{\circ}$ em contato com o globo ocular. Escudos infralabiais $9 / 9$, cinco deles em contato com as placas mentonianas. Primeiro par de escudos infralabiais tocam-se após a sinfisal. Nasal única. Loreal um pouco mais alta que longa. Fórmula ocular $1+2$, pós-oculares superiores e inferiores de tamanhos semelhantes. Fórmula temporal 2+3. Internasais tão largas quanto longas, um pouco menores que as pré-frontais. Pré-frontais um pouco mais largas que longas. Frontal pentagonal, mais longa que larga $(6,7 \times 4,4 \mathrm{~mm})$. Parietais longas, afilando-se posteriormente (7,5×4,8 mm). Maior distância entre a frontal e a rostral igual a 12,0 mm (39,4\% do Ccab). Distância da região superior da sutura entre os escudos parietais à tangente da rostral igual a 17,2 mm (56,5\% do Ccab). Olhos com pupila vertical elíptica, diâmetro longitudinal igual a 4,7 mm (90,3 \% da distância entre o olho e a tangente da rostral). Distância do olho à tangente da rostral igual a 5,2 mm, menor distância dorsal entre os olhos igual a 9,3 mm. Placas mentonianas anteriores menores que as posteriores (5,5 e 6,7 mm, respectivamente, no lado direito). Escamas dorsais quilhadas em 19/19/ 15 fileiras, com uma fosseta apicilar; 154 escamas ventrais. Placa cloacal dividida. Escamas subcaudais em 66 pares, finalizados por uma escama terminal pontiaguda.

Coloração em preservativo (Figuras 1 e 2): dorsalmente, o exemplar apresenta coloração marrom-clara amarelada, quase totalmente uniforme (Figura 1A). Cabeça um pouco mais es- cura dorsalmente (Figura 2A), com tênue linha pós-ocular escurecida delicada e fina, dirigindose para a comissura bucal (Figura 2B). A cabeça, na sua face ventral, é imaculada (Figura 2C). $\mathrm{O}$ ventre do corpo é levemente mais claro que o dorso, com dois pares de finas linhas escuras longitudinais paralelas, sendo um par em cada lado do ventre (Figura 1B). As linhas externas são mais evidentes que as internas. As linhas que compõe cada par estão separadas por um pequeno espaço claro, com delicadas manchas escuras, por vezes causando a impressão de linhas acessórias internas. Na região mediana do ventre, aparece mais um par de linhas bastante inconspícuo, não perceptível na cauda. A cauda, tanto ventral como dorsalmente, é semelhante ao corpo (Figura 1).

Variação entre os parátipos (2 exemplares): os dados referentes à folidose e às medidas dos parátipos estão sumarizados na Tabela 1. A coloração dos parátipos foi observada em animais fixados em formalina $10 \%$. Não há variação significativa no padrão de desenho e no colorido entre os parátipos e entre estes e o holótipo. O parátipo IB 52136 é um pouco mais claro que o holótipo, apresentando linhas longitudinais ventrais pouco conspícuas. O parátipo IB 52134 é jovem e não apresenta variações ontogenéticas de desenho ou colorido.

Etimologia: O epíteto específico almae é uma homenagem à herpetóloga Sílvia Alma Renata Wilma Lemos Romano-Hoge, pesquisadora aposentada do Laboratório de Herpetologia do Instituto Butantan, a quem muito nos honra homenagear.

\section{Discussão}

A taxonomia de Thamnodynastes sempre foi fonte de controvérsias entre pesquisadores, a partir da aceitação de sua prioridade em relação a Dryophylax Wagler, 1830. Amaral (1930) e Prado (1942) optaram por Dryophylax devido à prioridade de página (Wagler 1830: página 
Tabela 1 - Dados da folidose e morfometria do holótipo e parátipos de Thamnodynastes almae sp. nov. Escamas ou. escudos pares apresentados dos lados direito e esquerdo, separados por barra (/). CRC: comprimento rostrocloacal, Ccau: comprimento da cauda, Ccab: comprimento da cabeça, DO: número de fileiras de escamas dorsais a uma cabeça de distância da cabeça, no meio corpo e a uma cabeça de distância da cauda, apresentados nessa ordem, separados por barras (/). DP: desvio padrão. VE: número de escamas ventrais, SC: número de pares de escamas subcaudais, SL: número de escudos supralabiais (entre parênteses, número de SL em contato com o globo ocular), IL: número de escudos infralabiais (entre parênteses, número de IL em contato com mentonianas). Oculares e temporais anteriores e posteriores, apresentadas nessa ordem, separadas por + . $\mathrm{X}=$ média aritmética.

\begin{tabular}{|c|c|c|c|c|}
\hline & $\begin{array}{l}\text { Holótipo IB } 52135 \text { - } \\
\text { macho }\end{array}$ & $\begin{array}{c}\text { Parátipo IB } 52134 \text { - } \\
\text { fêmea }\end{array}$ & $\begin{array}{c}\text { Parátipo IB } 52136 \text { - } \\
\text { fêmea }\end{array}$ & $X \pm D P$ \\
\hline $\mathrm{CRC}(\mathrm{mm})$ & 657 & 275 & 595 & $509,0 \pm 205,0$ \\
\hline Ccau (mm) & 189 & 75 & 166 & $143,3 \pm 60,3$ \\
\hline Ccab (mm) & 30,4 & 17,1 & 31,3 & $26,3 \pm 7,9$ \\
\hline DO & $19 / 19 / 15$ & $19 / 19 / 15$ & $19 / 19 / 15$ & \\
\hline VE & 154 & 144 & 159 & $152,3 \pm 7,6$ \\
\hline SC & $66 / 66$ & $59 / 59$ & $63 / 63$ & $62,6 \pm 3,5$ \\
\hline SL & $8 / 8\left(4^{a}, 5^{a}\right)$ & $8 / 8\left(4^{a}, 5^{a} / 4^{a}, 5^{a}\right)$ & $8 / 8\left(4^{\mathrm{a}}, 5^{\mathrm{a}} / 4^{\mathrm{a}}, 5^{\mathrm{a}}\right)$ & \\
\hline IL & $\begin{array}{l}8 / 9\left(1^{\mathrm{a}}-5^{\mathrm{a}}\right), 6^{\mathrm{a}} \text { e } 7^{\mathrm{a}} \\
\text { fundidas do lado direito }\end{array}$ & $9 / 9\left(1^{a-}-5^{a} / 1^{a}-5^{a}\right)$ & $10 / 9\left(1^{\mathrm{a}}-6^{\mathrm{a}} / 1^{\mathrm{a}}-5^{\mathrm{a}}\right)$ & \\
\hline Nasal & única & dividida/única & única & \\
\hline Oculares & $1+2 / 1+2$ & $2+2 / 2+2$ & $2+2 / 2+2$ & \\
\hline Temporais & $2+3 / 2+3$ & $2+2 / 2+3$ & $2+3 / 2+3$ & \\
\hline
\end{tabular}

181 para Dryophylax e página 182 para Thamnodynastes). Esses pesquisadores ignoraram a autoridade de Günther (1858), primeiro revisor, que deu preferência a Thamnodynastes. Parker (1935) resgatou a proposta de Günther (1858) e esclareceu oportunamente essa questão taxonômica.

Como citado por Vanzolini et al. (1980) e Cei (1993), há várias espécies a serem descritas neste gênero, sendo necessária uma revisão taxonômica, mesmo após várias descrições de espécies novas e revalidações ocorridas nos últimos anos (ver Introdução). Franco (1999) ci- tou outras seis espécies ainda não-descritas, quatro das quais foram abordadas em seu trabalho, em que examinou exemplares de uma área geográfica restrita, considerando-se a área de ocorrência das espécies do gênero. $T$ almae sp. nov. não foi abordada por Franco (1999).

Peters e Orejas-Miranda (1970) citaram Thamnodynastes pallidus como ocorrente nas Guianas, Brasil, Peru e Venezuela; porém, os poucos registros confiáveis estão, na maioria das vezes, relacionados à hiléia Amazônica e à bacia costeira das Guianas (Cunha e Nascimento 1978, Hoogmoed 1979, 1983, Abuys 1986, 
Chippaux 1986, Silva e Sites 1995, Myers e Donnelly 1997). Gorzula e Ayarzagüena (1996) e Myers e Donnelly (1997) confirmaram a ocorrência de T. pallidus na Amazônia Venezuelana. Pérez-Santos e Moreno (1988) referiram-se a $T$. pallidus como uma espécie amplamente distribuída na Colômbia, tanto em áreas ao leste como ao oeste dos Andes, excetuando-se a planície do Pacífico. Nesse livro, Pérez-Santos e Moreno (1988) atribuíram escama cloacal dividida para os indivíduos da espécie, e os dados merísticos foram provavelmente obtidos de outras referências. Entretanto, Pérez-Santos e Moreno (1989) comentaram que T. pallidus apresenta escama cloacal inteira. Não está claro se os indivíduos dessa população possuem escama cloacal inteira ou dividida, e, neste último caso, não seriam T. pallidus. Silva e Sites (1995) citaram a existência de exemplares dessa espécie na coleção do Dr. J. J. Silva Haddad (Hospital Regional de Letícia, Colômbia). Como Silva e Sites (1995) não se detiveram na confirmação da identificação desses exemplares e, sendo confusa a taxonomia do gênero, é prudente aguardar confirmação desse registro para a Colômbia. A escama cloacal inteira consiste em um bom caráter diagnóstico para essa espécie, como pode ser observado nas Tabelas 2 e 3. Os exemplares citados por Dixon e Soini (1977), de Iquitos, Peru, provavelmente não são $T$. pallidus, pois apresentam escama cloacal dividida. Não foi encontrada nenhuma evidência concreta da ocorrência de T. pallidus no Peru; assim, esse registro também necessita ratificação. Essa espécie não foi encontrada na Reserva Ducke ou na reserva do INPA-WWF, próximo à Manaus (AM), onde foram realizadas amostragens intensivas (Zimmerman e Rodrigues 1990, Martins e Oliveira 1998), não havendo conhecimento de qualquer outra citação para a região central da Amazônia. Durante as atividades de resgate de fauna da Usina Hidroelétrica de Samuel, em Rondônia, não foram coletados exemplares dessa espécie (Silva 1993). Silva (1993) citou o exemplar IB 22155 , proveniente do rio Guaporé, Forte Príncipe da
Beira, pouco abaixo da confluência do rio Branco, na fronteira com a Bolívia (Bokermann 1966), que teria sido coletado pelo próprio W. C. A. Bokermann. Infelizmente, esse exemplar não foi localizado na Coleção do Instituto Butantan para que sua identidade pudesse ser confirmada. Silva e Sites (1995) referiram-se a T. pallidus da Coleção Herpetológica do Instituto Butantan, proveniente da Usina Hidroelétrica de Tucuruí, Pará. Contudo, não foram localizados exemplares ou registros dessa espécie para essa localidade na referida coleção. O espécime (IB 18533), procedente de Tarauacá, Acre, marca atualmente o extremo sul de distribuição de T. pallidus na Amazônia.

Vanzolini et al. (1980) e Vitt e Vangilder (1983) registraram a ocorrência de T. pallidus em Exu, Pernambuco, região semi-árida do nordeste brasileiro; todavia, esses exemplares apresentam escama cloacal dividida e correspondem a uma espécie muito distinta e ainda não descrita (Thamnodynastes sp. 5), como sugerido por Cunha e Nascimento (1981) e R. Thomas (apud Vitt e Vangilder 1983). Silva e Sites (1995) denominaram de T. pallidus a mesma espécie não-descrita (Thamnodynastes sp. 5), citada por Vanzolini et al. (1980) e Vitt e Vangilder (1983), como ocorrente na área agora ocupada pela UHE Luiz Gonzaga, entre os estados de Pernambuco e Bahia. Cordeiro e Hoge (1973) listaram dois espécimes que se enquadram na descrição de T. pallidus, sendo um deles do Museu de Zoologia da Universidade de São Paulo (MZUSP 5005), de Vicência (07 39' S - 35 19’ W, 120 m), Pernambuco. Wagler (1824), quando descreveu Natrix punctatissima (= T. pallidus), citou Bahia, Brasil, como localidade-tipo. Adicionalmente, o espécime IB 1847, identificado como $T$. pallidus, coletado pelo Dr. Pirajá da Silva, tem apenas Bahia como procedência. Assim, apesar dos poucos registros, essa espécie ocorre nas bordas norte e sul da Bacia Amazônica (Venezuela e leste do Pará, Brasil), e drenagens costeiras do Suriname e Guiana Francesa. No nordeste brasileiro, os poucos exemplares co- 


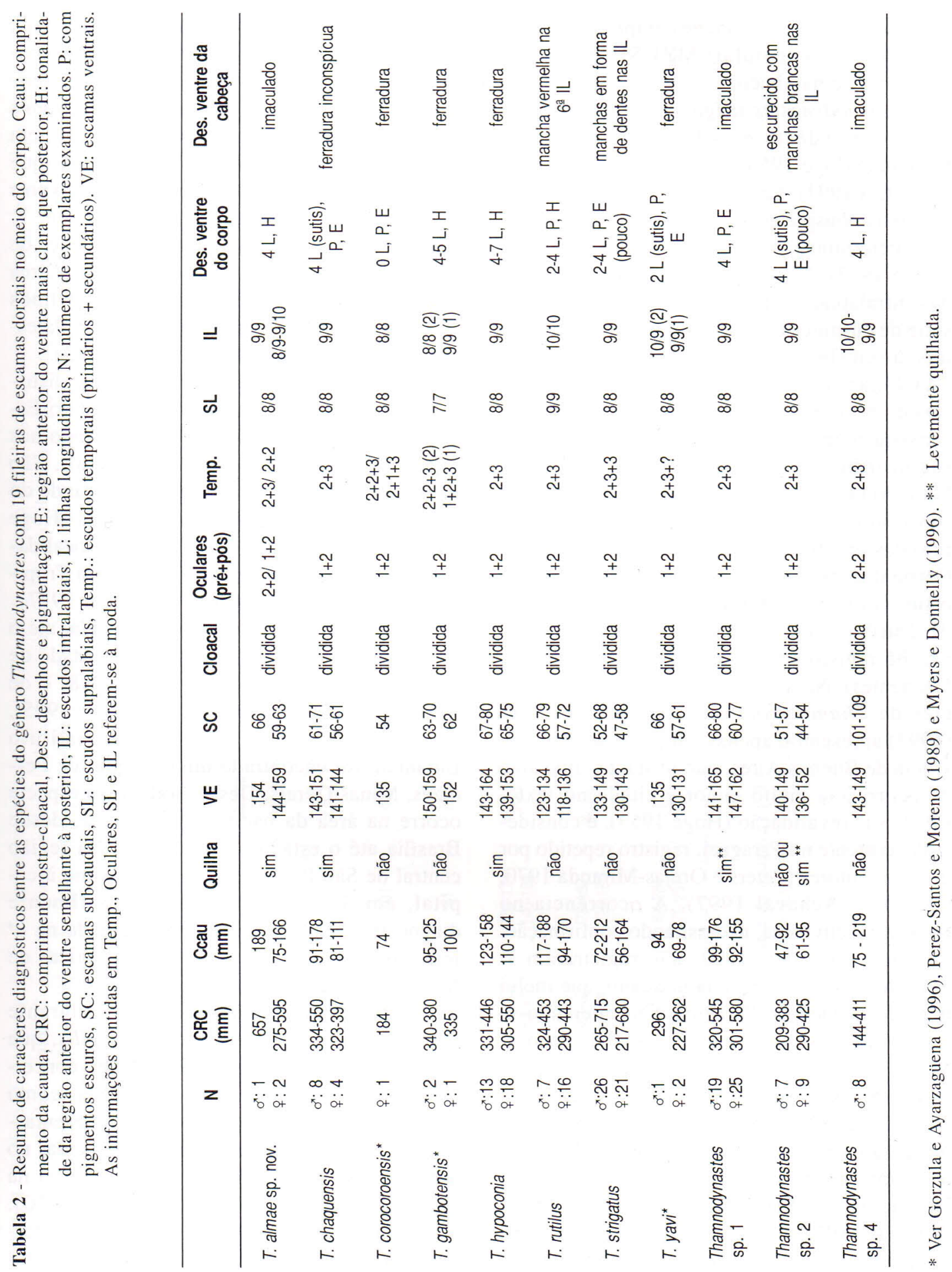


nhecidos são de localidades imprecisas, com exceção do exemplar MZUSP 5005, de Vicência, Pernambuco.

Thamnodynastes strigatus é registrada para o sul e o sudeste brasileiros, Argentina e Paraguai (Hoge 1953, Peters e Orejas-Miranda 1970, Cei 1993). Embora essa espécie seja uma das mais conspícuas do gênero e, portanto, de fácil determinação, só foi revalidada em 1953 (Hoge 1953). O padrão de desenho e colorido das infralabiais é diagnóstico, lembrando uma série de cúspides direcionadas para baixo e para trás, à semelhança de dentes (Tabela 2, Figura 3A). O caos taxonômico reinante entre as espécies do gênero gerou determinações errôneas e, conseqüentemente, a atribuição equivocada de sua distribuição geográfica. Como citado por Giraudo (1997), esse táxon teve a distribuição superestimada na Argentina, sendo, de fato, próprio das províncias de Missiones e nordeste de Corrientes, estendendo-se, pelo rio Uruguai, até o sul (Giraudo [1997] não apontou o limite sul de distribuição e, no mapa a que ele se refere, não há registros mais ao sul que nordeste de Corrientes). No mapa de distribuição das espécies de Thamnodynastes na Argentina, Cei (1993) apresentou apenas um ponto para a província de Buenos Aires, não obstante, uma área de ocorrência muito maior é citada no texto. Desde sua revalidação (Hoge 1953), é considerada ocorrente no Paraguai, registro repetido por diversos autores (Peters e Orejas-Miranda 1970, Cei 1993, Achaval 1997). A ocorrência no Paraguai é duvidosa, necessitando confirmação. Leynaud e Bucher (1999) não registraram $T$. strigatus para o chaco sulamericano, que inclui mais da metade do Paraguai. Considerando-se a ausência dessa espécie no Pantanal de Poconé, Mato Grosso, na bacia do rio Paraguai (Strussmann e Sazima 1993), e os dados de Giraudo (1997), espera-se sua ocorrência apenas para o extremo sul do Paraguai. Vários autores citaram a ocorrência dessa serpente no Uruguai (e.g. Lema e Fabián-Beurmann 1977, Achaval 1997, e referências aí citadas), mas, como observamos nas fotografias apresentadas por Achaval (1997) e Achaval e Olmos (1997), há os constantes e compreensíveis erros de identificação com espécies recentes ou não descritas. Os exemplares figurados nesses trabalhos referem-se a T. chaquensis. Curiosamente, em Achaval e Olmos (1997), a foto em destaque mostra a cabeça de um exemplar de T. strigatus e a foto principal, um exemplar de $T$. chaquensis. Desse modo, embora a presença de T. strigatus no Uruguai esteja confirmada (Lema e Fabián-Beurmann 1977, Achaval e Olmos 1997, Achaval 1997), a real distribuição da espécie nesse país deve ser melhor estudada.

No Brasil, Thamnodynastes strigatus distribui-se pelas regiões serranas do estado do Espírito Santo, em direção ao Sul, ocorrendo nos estados do Rio de Janeiro, Minas Gerais, São Paulo, Paraná, Santa Catarina e Rio Grande do Sul, onde ocupa, também, áreas baixas (Hoge 1953, Marques et al. 2001). Todas as localidades brasileiras estão dentro do Domínio Tropical Atlântico e das Coxilhas (Ab’Saber 1977).

Thamnodynastes rutilus é conhecida, até o momento, de algumas localidades do estado de São Paulo (Prado 1942, Vanzolini 1948) e de Brasília, Distrito Federal (Silva e Sites 1995). $\mathrm{Na}$ Coleção Herpetológica do Instituto Butantan, foi encontrado um exemplar de Perdizes, Minas Gerais. Desse modo, essa espécie ocorre na área da bacia do rio Paraná, desde Brasília até o estado de São Paulo. Na região central de São Paulo, ocorre até próximo à capital, em São Roque. Pode ser facilmente diagnosticada pela mancha avermelhada na $6^{\text {a }}$ infralabial (Figura 3C) e por características de folidose apresentadas na Tabela 2.

Thamnodynastes hypoconia foi, durante muitos anos, confundida com T. strigilis, que ainda abrangia outras espécies sob seu conceito. Diversas espécies eram determinadas como T. strigilis, pois os exemplares que apresentassem 19 fileiras de escamas dorsais quilhadas no meio do corpo eram identificados como tal na chave de Peters e Orejas-Miranda (1970). Vanzolini et. al. (1980) e Vanzolini (1986) destacaram, com propriedade, o problema da cha- 


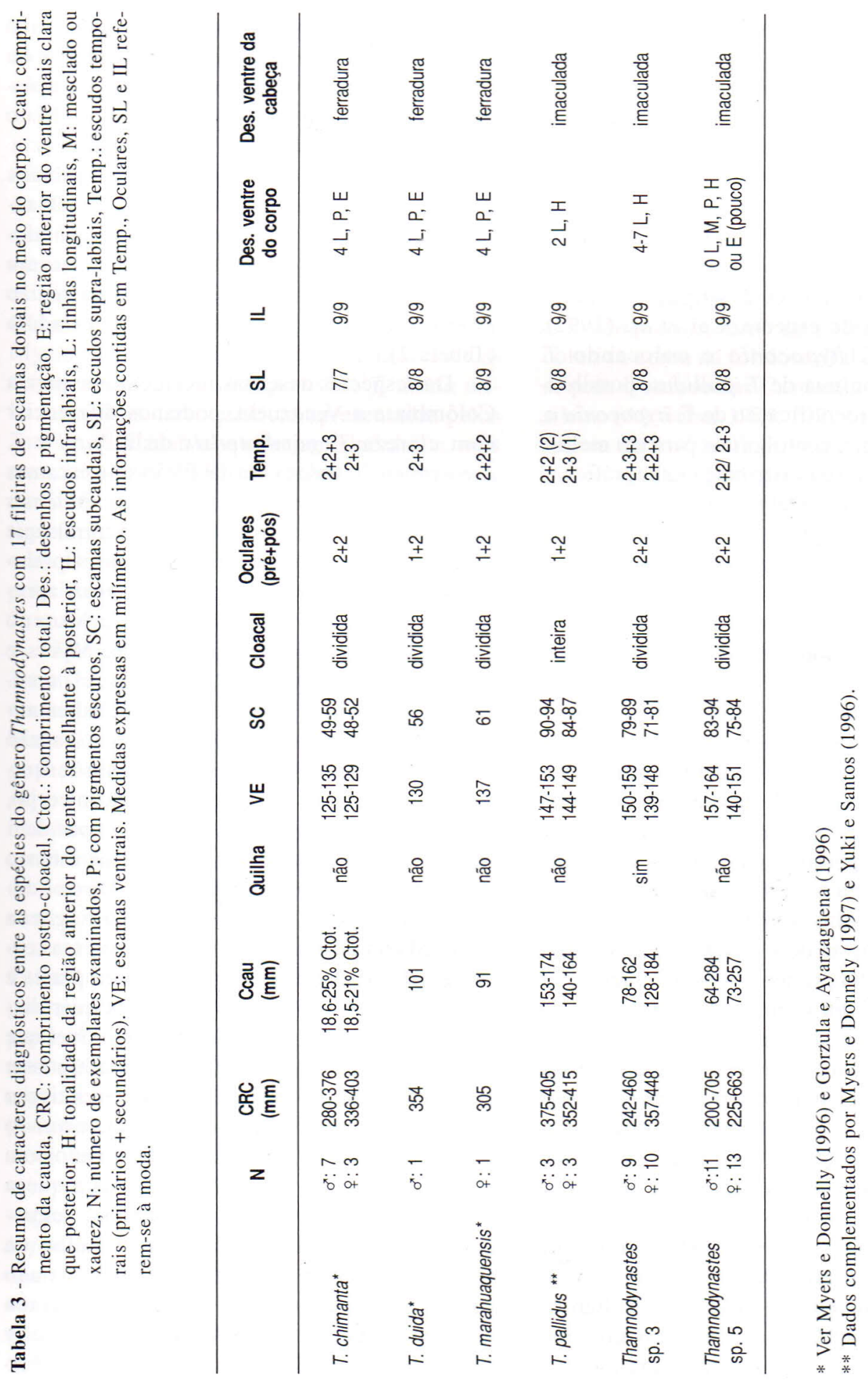


ve de Peters e Orejas-Miranda (1970), que abrange poucas espécies dentre as muitas que de fato existem, o que a torna ineficaz. Adicionalmente, Amaral (1926) colocou sob o nome $T$. pallidus uma série de táxons com 17 ou 19 escamas dorsais no meio do corpo. Posteriormente, Amaral (1930) usou Dryophylax pallidus strigilis e D. p. pallidus como subespécies, agravando os problemas de identificação. Roze (1958) elevou novamente T. strigilis e T. pallidus à categoria de espécie. Cei et al. (1992), revalidando $T$. hypoconia e colocando $T$. strigilis na sinonímia de T. pallidus, possibilitaram a correta identificação de T. hypoconia e, conseqüentemente, contribuíram para um melhor conhecimento de sua distribuição geográfica.

Marques et al. (2001) citaram a ocorrência de T. hypoconia na Mata Atlântica do sul e sudeste do Brasil, mais precisamente nos estados do Rio de Janeiro, São Paulo, Paraná e Santa Catarina. Na Coleção Herpetológica do Instituto Butantan, há exemplares de T. hypoconia procedentes de uma ampla área de distribuição nos estados de Pernambuco, Goiás, Mato Grosso, Mato Grosso do Sul, Minas Gerais, Espírito Santo, Rio de Janeiro, São Paulo, Paraná, Santa Catarina e Rio Grande do Sul (Apêndice I).

Thamnodynastes chaquensis foi recentemente descrita por Bergna e Alvarez (1993), tendo sua ocorrência registrada para as províncias do Chaco, Formosa, leste de Salta, norte de Santa Fé e noroeste de Corrientes, na Argentina. Foi citada pela primeira vez no Paraguai por Giraudo (1996); na Coleção Herpetológica do Instituto Butantan, também há um exemplar de Bahia de Assunção, Paraguai. Para o Uruguai, pudemos observar uma fotografia em Achaval e Olmos (1997), quando se referem a T. strigatus, sendo que a fotografia maior ilustra um exemplar de $T$. chaquensis. Strussmann e Sazima (1993) referiram-se a Thamnodynastes sp. para o Pantanal brasileiro, distinguindo-a da espécie considerada válida na ocasião, $T$. strigilis, por contagens de escamas, padrão de desenho e comportamento. A espécie em questão é ainda ilustrada por meio de uma fotogra- fia, permitindo seu reconhecimento seguro como T. chaquensis. Na Coleção Herpetológica do Instituto Butantan, foram encontrados exemplares procedentes do Brasil, dos estados do Mato Grosso e Mato Grosso do Sul (Apêndice I).

Thamnodynastes chaquensis possui padrões de desenho e colorido do corpo muito semelhantes aos de Thamnodynastes sp. 2, distingüindose desta por apresentar escamas subcaudais em maior número e padrão de desenho na região inferior da cabeça com mancha em ferradura (Tabela 2).

Das espécies descritas recentemente para a Colômbia e a Venezuela, podemos diferenciar com clareza $T$. gambotensis de $T$. yavi e $T$. corocoroensis, todas com 19 fileiras de escamas dorsais lisas no meio do corpo. T. gambotensis apresenta maior número de escamas ventrais que T. yavi e T. corocoroensis e sete placas supralabiais, enquanto T. yavi e T. corocoroensis apresentam oito placas (Pérez-Santos e Moreno 1989, Gorzula e Ayarzagüena 1996, Myers e Donnelly 1996). T. yavi e T. corocoroensis compartilham uma série de características, salientando-se que $T$. corocoroensis perdeu o padrão lineado ventral e que T. yavi apresenta resquícios de duas linhas na região anterior do corpo, sendo o ventre dessas espécies coberto por denso pontilhado escuro que se torna mais intenso à medida que se aproxima da cauda (Pérez-Santos e Moreno 1989, Gorzula e Ayarzagüena 1996, Myers e Donnelly 1996). Como essas espécies são conhecidas por poucos exemplares e como os autores não apresentam qualquer distinção segura entre esses táxons, é possível que sejam sinônimos. A averiguação dessa hipótese deve ser feita com base nos exemplares-tipo e em séries maiores. Outro problema envolvendo T. yavi e T. corocoroensis está relacionado com a prioridade entre os nomes, uma vez que a sinonimização venha a ser confirmada. Segundo Myers e Donnelly (1997), o trabalho de Gorzula e Ayarzagüena (1996), embora datado de junho de 1995, só foi distribuído mais de um ano depois, e o trabalho de Myers e Donnelly (1996) foi publicado em junho de 1996, eviden- 
ciando a necessidade de averiguação de qual obra foi distribuída primeiro para o estabelecimento da prioridade taxonômica.

Dentre as espécies com 17 fileiras de escamas dorsais no meio do corpo, podemos diferenciar com clareza Thamnodynastes chimanta de $T$. duida e T. marahuaquensis. T. chimanta apresenta duas escamas pré-oculares e sete escamas supralabiais, enquanto as demais espécies apresentam uma pré-ocular e oito supralabiais (Roze 1958, Gorzula e Ayarzagüena 1996, Myers e Donnelly 1996). Não foi possível a distinção entre T. marahuaquensis e T. duida utilizando-se as características apresentadas pelos autores. É plausível que sejam sinônimos, mas essa atitude taxonômica só deve ser tomada a partir de um exame cuidadoso dos exemplarestipo (apenas um de cada espécie) e séries maiores. O mesmo problema de estabelecimento de prioridade taxonômica observado em T. yavi e $T$. corocoroensis existe entre esses táxons.

Thamnodynastes sp. 1 (Thamnodynastes sp. 3 em Franco 1999) é muito comum desde o norte da Bahia, em Paulo Afonso, a Corumbá, Mato Grosso do Sul, e até Montevidéu, no Uruguai. Ocorre nas áreas de influência atlântica do sul e sudeste brasileiro, sendo mais abundante nas áreas de floresta ombrófila densa e menos abundante nas áreas de floresta semidecidual e de cerrado. Aparentemente, o nome Coluber nattereri Mikan, 1820 pode ser adequado para esse táxon. Mikan (1820) citou "Sebastiano Polim” como sua localidade-tipo, mas muito provavelmente estava se referindo a Sebastianópolis (U. Caramaschi, com. pess.), atualmente conhecida como Rio de Janeiro (RJ), onde essa espécie é freqüente. A descrição original não possui nada que impossibilite atribuir esse nome a esse animal; porém, a atribuição do nome correto a essa espécie deve ser feita após a localização de seu tipo. É muito semelhante a $T$. hypoconia, mas esta apresenta a porção ventral da cabeça com manchas, às vezes em forma de ferradura (Figura 3B), ventre com região anterior e posterior homogêneas, com linhas longitudinais muito conspícuas, e escamas dorsais fortemente quilhadas (Tabela 2). Por sua vez, Thamnodynastes sp. 1 apresenta a porção ventral da cabeça imaculada, a região posterior do ventre mais escura que a anterior, linhas longitudinais menos conspícuas e escamas dorsais fracamente quilhadas (Tabela 2).

Thamnodynastes sp. 2 é um animal de porte robusto, com as regiões mentoniana e gular escurecidas e escudos infralabiais manchados de branco. Como dito anteriormente, é semelhante a $T$. chaquensis, tanto no padrão de desenho e colorido como na folidose (Tabela 2). Distribuise pelo Domínio das Caatingas do nordeste brasileiro (Ab’Saber 1974, 1977), nas áreas de drenagem do rio São Francisco e drenagem costeira dos estados da Bahia e Rio Grande do Norte. Vanzolini et al. (1980) descreveram esta espécie, atribuindo-lhe o nome de T. strigilis. Isso é facilmente compreensível devido ao fato da chave de identificação de Peters e OrejasMiranda (1970) considerar todos os indivíduos com 19 fileiras de escamas dorsais quilhadas no meio do corpo como T. strigilis. Essa espécie está sendo descrita pelos autores deste artigo.

Thamnodynastes sp. 3 (Thamnodynastes sp. 4 em Franco 1999) é uma serpente com coloração extremamente clara, escamas dorsais fortemente quilhadas arranjadas em 17 fileiras no meio do corpo e duas placas pré-oculares. É conhecida apenas de duas localidades, Agachi, no Mato Grosso do Sul, e Curral Grande, no município de Monte Alegre, Pará. Essas duas localidades estão a mais de 2.000 km de distância em linha reta. Agachi localiza-se na borda do Pantanal Sul, enquanto Monte Alegre está na margem esquerda do rio Amazonas. Aparentemente, a espécie é muito comum em Monte Alegre, havendo 19 exemplares dessa localidade na coleção do Instituto Butantan. Para Agachi, há o registro de apenas um exemplar em coleção. Essa espécie também está sendo descrita pelos autores deste trabalho.

Thamnodynastes sp. 4 ocorre em regiões serranas dos estados de São Paulo e Rio de Janeiro. Ocorre na Serra de Paranapiacaba, desde o sul do estado de São Paulo, em Guapiara, até 
as proximidades da capital, em Itapecerica da Serra. Na Serra do Mar, ocorre desde Boracéia, em Salesópolis, até Areias, no vale do rio Paraíba, contíguo à Serra da Bocaina. No estado do Rio de Janeiro, é conhecida apenas para o município de Teresópolis, na Serra dos Órgãos. Sua área de distribuição geográfica encontra-se dentro do Domínio Tropical Atlântico (Ab’Saber 1977).

Thamnodynastes sp. 5 (Thamnodynastes sp. 1 em Franco 1999) distribui-se pela região norte do estado da Bahia e em Petrolândia, estado de Pernambuco, nas proximidades da Usina Hidroelétrica Luiz Gonzaga (Ex - UHE de Itaparica), no rio São Francisco e Exu, Serra do Araripe, estado de Pernambuco (Vanzolini et al. 1980). Todas essas localidades estão contidas no Domínio das Caatingas (Ab’Saber 1974, 1977). Estas duas últimas espécies estão sendo descritas pelos autores deste trabalho em colaboração com os Drs. Otávio A.V. Marques (Instituto Butan$\tan$ ) e Ivan Sazima (Universidade Estadual de Campinas).

\section{Agradecimentos}

Agradecemos ao Dr. Ronaldo Fernandes (Museu Nacional, UFRJ), pela leitura crítica e empréstimo de material, a Hebert Ferrarezzi (Instituto Butantan), pelas sugestões, a Ricardo A.K. Ribeiro, pela tomada de dados e sugestões, a Antônio Bordignon, pelo auxílio no tratamento das imagens, aos Drs. Otávio A.V. Marques (Instituto Butantan) e Ivan Sazima (UNICAMP), por discussões, aos Drs. Marcos Di Bernardo (Museu de Ciências e Tecnologia da PUC de Porto Alegre) e Márcio Borges Martins (Fundação Zoobotânica do Rio Grande do Sul, Porto Alegre), pela confecção do mapa, ao Dr. Rogério Bertani, pelo empréstimo de fotografia, aos funcionários e estagiários do Instituto Butantan, em nome de Valdir J. Germano, pelo auxílio em diversas etapas deste trabalho, ao Dr. Jaime Bertoluci (editor) e aos revisores deste artigo, pela valiosa contribuição crítica, sugestões e correções, e à FAPESP, pelo subsídio financeiro.

\section{Referências Bibliográficas}

Ab’Saber, A. N. 1974. O domínio morfoclimático semiárido das caatingas brasileiras. Geomorfologia 43: 139.

Ab’Saber, A. N. 1977. Os domínios morfoclimáticos na América do Sul. Primeira aproximação. Geomorfologia 52: 1-21.

Abuys, A. 1986. The snakes of Surinam, part XV: Subfamily Xenodontinae (Genera Tantilla, Thamnodynastes, and Tripanurgos). Litteratura Serpentium 6: 107-116.

Achaval, F. 1997. Actualización sistemática y sinonímica de los reptiles del Uruguai com comentários $e$ distribucion. Tese de Doutoramento não-publicada. Universidad de la República, Faculdad de Ciências, Montevideo, Uruguai.

Achaval, F. e A. Olmos. 1997. Anfíbios y Reptiles del Uruguai. Barriero e Ramos S. A. Série Fauna 1. 128 pp.

Amaral, A. 1926. Notas de ophiologia. $1^{\text {a }}$ nota de ophiologia. Sobre a invalidez de um gênero e algumas espécies de ophidios sul-americanos. Revista do $\mathrm{Mu}$ seu Paulista 14: 17-33.

Amaral, A. 1930. Estudos sobre ofídios Neotrópicos. XVIII. Lista remissiva dos ophidios da região Neotrópica. Memórias do Instituto Butantan 4: 127271, 1929.

Bailey, J. R. 1966. A redescription of the snake Calamodontophis paucidens. Copeia 1966: 885-886.

Bailey, J. R. 1967a. Modes of evolution in New World opisthoglyph snakes. Memórias do Instituto Butantan 33: 67-72 (1966).

Bailey, J. R. 1967b. The synthetic approach to colubrid classification. Herpetologica 23: 155-161.

Bailey, J. R. 1981. Notes on the genus Thamnodynastes. In Simpósio Internacional sobre Serpentes em Geral e Artrópodes Peçonhentos, $1^{\circ}$ Abstracts. São Paulo, Instituto Butantan (Livro de Resumos).

Beçak, W. e M. L. Beçak. 1969. Cytotaxonomy and chromosomal evolution in Serpentes. Cytogenetics 8: 149-150.

Bellagamba, P.J. e L. E. Vega. 1996. Geographic Distribution. Thamnodynastes hypoconia (Cateye Coluber). Argentina: Buenos Aires. Herpetological Review 27: 36.

Bergna, S. e B. Alvarez. 1993. Descripción de una nueva especie de Thamnodynastes (Reptilia: Serpentes, Colubridae) del nordeste argentino. Facena 10: 5-18.

Bokermann, W. C. A. 1966. Lista Anotada das Localidades Tipo de Anfíbios Brasileiros. Serviço de Ducumentação - RUSP, São Paulo, 183 pp. 
Cadle, J. E. 1984a. Molecular systematics of Neotropical xenodontine snakes: I. South American xenodontines. Herpetologica 40: 8-20.

Cadle, J. E. 1984b. Molecular systematics of Neotropical xenodontine snakes: II. South American xenodontines. Herpetologica 40: 21-30.

Cadle, J. E. 1985. The Neotropical colubrid snake fauna (Serpentes; Colubridae): lineage components and biogeography. Systematic Zoology 34: 1-20.

Cadle, J. E. 1987. The geographic distribution of snakes: problems in phylogeny and zoogeography. Pp. 77-105 in R. A. Seigel, J. T. Collins e S. S. Novak (eds.), Snakes: ecology and evolutionary biology. New York, Macmillan Press.

Cadle, J. E. e H. C. Dessauer. 1985. Biochemical evolution in South America xenodontine snakes. Abstracts, Annual Meeting of the American Society of Ichthyologists and Herpetologistis 47: 1-47.

Cadle, J. E. e H. W. Greene. 1993. Phylogenetic patterns, biogeography, and the ecological structure of Neotropical snake assemblages. Pp. 281-293 in R. E. Ricklefs e D. Schluter (eds.), Species Diversity in Ecological Communities - historical and geographical perspectives. Chicago, University of Chicago Press.

Cei, J. M. 1993. Reptiles del noroeste y este de la Argentina. Herpetofauna de las selvas subtropicales, Puna y Pampas. Torino, Museo Regionale di Scienze Naturali (Monografie 14). 949 pp.

Cei, J. M., S. Bergina e B. Alvarez. 1992. Nueva combinación para el genero Thamnodynastes (Serpentes, Colubridae) de Argentina. Facena 9: 123-134.

Chippaux, J. P. 1986. Les Serpents de la Guyane Française. Paris, Orstom. 165 pp.

Cordeiro, C. L. e A. R. Hoge. 1973. Contribuição ao conhecimento das serpentes do estado de Pernambuco. Memórias do Instituto Butantan 37: 261-290.

Cunha, O. R. e F. P. Nascimento. 1978. Ofídios da Amazônia. X - As cobras da região leste do Pará. Publicações Avulsas do Museu Paraense Emílio Goeldi, Belém 31: 1-218.

Cunha, O. R. e F. P. Nascimento. 1981. Ofídios da Amazônia. XIII - Observações sobre a viviparidade em ofídios do Pará e Maranhão (Ophidia: Aniliidae, Boidae, Colubridae e Viperidae). Boletim do Museu Paraense Emílio Goeldi, Série Zoologia 109: 1-20.

Dessauer, H. C., J. E. Cadle e R. Lawson. 1987. Patterns of snake evolution suggested by their proteins. Fieldiana: Zoology, new series 34: 1-34.

Dixon, J. R. e P. Soini. 1977. The reptiles of the upper Amazon basin, Iquitos region, Peru. II. Crocodilians, turtles and snakes. Contributions in Biology and Geology, Milwaukee Publications Museum 12: 1-91.
Dowling, H. G. 1951. A proposed standard system of counting ventral in snakes. British Journal of Herpetology 1: 97-99.

Dowling, H. G. e W. E. Duellman. 1978. Systematic Herpetology: a synopsis of families and higher categories. New York, Herpetological Information Search Systems Publications. 240pp.

Dowling, H. G., R. Higton, G. C. Maha e L. R. Maxson. 1983. Biochemical evaluation of colubrid snake phylogeny. Journal of Zoology 201: 309-329.

Dunn, E. R. 1928. A tentative key and arrangement of the American genera of Colubridae. Bulletin of the Antivenin Institute of America 2: 18-24.

Ferrarezzi, H. 1994. Uma sinopse dos gêneros e classificação das serpentes (Squamata) II. Família Colubridae. Pp. 81-91 in L. B. Nascimento, A. T. Bernardes e G. A. Cotta (eds.), Herpetologia no Brasil, 1. Belo Horizonte, PUC-MG, Fundação Biodiversitas e Fundação Ezequiel Dias.

Franco, F. L. 1999. Relações filogenéticas entre os gêneros da tribo Tachymenini Bailey, 1967 (Serpentes, Colubridae). Tese de Doutorado Não-publicada. São Paulo, Universidade de São Paulo.

Giraudo, A. R. 1996. Geographic Distribution. Thamnodynastes chaquensis (Chaco Coastal House snake). Paraguay: Neembucu. Herpetological Review 27: 215.

Giraudo, A. R. 1997. Composición, distribución y caracterización biogeografica de los colúbridos (Serpentes: Colubridae) de las províncias de Misiones y Norte de Corrientes (Argentina) y su aplicación en la conservación. Tese de Doutoramento não-publicada. Córdoba, Universidad Nacional de Córdoba, Argentina.

Gorzula, S. e J. Ayarzaguena. 1996. Dos nuevas especies del genero Thamnodynastes (Serpentes; Colubridae) de los tepuyes de la Guayana Venezuelana. Publicaciones de la Associacion de Amigos de Donana 6: 1-17, 1995.

Günther, A. 1858. Catalogue of Colubrine snake in the collection of British Museum. London, Trustees of the British Museum. 281 pp.

Hoge, A. R. 1953. Notas herpetológicas. Revalidação de Thamnodynastes strigatus (Günther, 1858). Memórias do Instituto Butantan 24: 157-172 (1952).

Hoogmoed, M. S. 1979. The herpetofana of the Guianan region. Pp. 241-279 in W. E. Duellman (ed.), The South American Herpetofauna: it's origin, evolution and dispersal. Lawrence, Museum of Natural History, The University of Kansas. (Monograph n. 7).

Hoogmoed, M. S. 1983. Snakes of the Guianan region. Memórias do Instituto Butantan 46: 219-254 (1982).

Jenner, J. 1981. A Zoogeographic Study and the Taxonomy of the Xenodontine Colubrid Snakes. Tese de Doutoramento não-publicada. New York University, USA. 
Jenner, J. V. e H. G. Dowling. 1985. Taxonomy of the Americam xenodontine snakes: the tribe Pseudoboini. Herpetológica 41: 161-72.

Lema, T. e M. E. Fabian-Beurmann. 1977. Levantamento preliminar dos répteis da região da fronteira BrasilUruguai. Iheringia, série Zoologia 50: 61-92.

Leynaud, G. C. e E. H. Bucher. 1999. La fauna de serpientes del chaco sudamericano: diversidad, distribucion geografica y estado de conservacion. Academia Nacional de Ciências. Córdoba, Argentina, Miscelanea $\mathrm{n}^{\circ}$ 98: 1-46.

Marques, O. A. V., A. Eterovic e I. Sazima. 2001. Serpentes da Mata Atlântica - guia ilustrado para a Serra do Mar. Ribeirão Preto, Holos. 184 pp.

Martins, M. e M. E. Oliveira. 1998. Natural history of snakes in forests of the Manaus region, Central Amazonia, Brazil. Herpetological Natural History 6: 78-150.

McDowell, S. B. 1987. Systematics. Pp. 3-50 in R. A. Siegel, J. T. Collins e S. S. Novak (eds.), Snakes: ecology and evolutionary biology. New York, MacMillan Press.

Mikan, J. C. 1820. Delectus florae at faunae brasiliensis. Viena, Typ. Antonii traus. 47 pp.

Myers, C. W. e M. A. Donnelly. 1996. A new herpetofauna from Cerro Yaví, Venezuela: First results of the Robert G. Goelet American Museum-Terramar expedition to the northwestern Tepuis. American Museum Novitates 3172: 1-56.

Myers, C. W. e M. A. Donnelly. 1997. A Tepui herpetofauna on a granitic mountain (Tamacuari) in the borderland between Venezuela and Brazil: report from the Phipps Tapirapecó Expedition. American Museum Novitates 3213: 1-71.

Parker, H. W. 1935. The frogs, lizards and snakes of British Guiana. Proceedings of Zoological Society 1935: 505530 .

Pérez-Santos, C. e A. G. Moreno. 1988. Ofídios de Colombia. Bolletino del Museo Regionale di Scienze Naturali, Torino 6: 1-517.

Pérez-Santos, C. e A. G. Moreno. 1989. Una nueva especie de Thamnodynastes (Serpentes: Colubridae) en el norte de Colombia. Bolletino del Museo Regionale di Scienze Naturali, Torino 7: 1-9.

Peters, J. A. 1964. Dictionary of Herpetology - a brief and meaningful definition of words and terms used in Herpetology. New York, Hafner Publishing Company. $392 \mathrm{pp}$.

Peters, J. A. e B. Orejas-Miranda. 1970. Catalogue of Neotropical Squamata. Part I. Snakes. Bulletin of United States National Museum 297: 1-347.

Prado, A. 1942. Serpentes do gênero Dryophylax, com a descrição de uma nova espécie. Ciência, México 3: 204-205.

Roze, J. A. 1958. Los reptiles de Chimanta Tepui (Estado Bolivar, Venezuela) colectados por la expedición botanica del Chicago Natural History Museum. Acta Biologica Venezuelica 2: 299-314.

Shine, R. 1985. The evolution of viviparity in reptiles: an ecological analysis. Pp. 605-694 in C. Gans e F. Billet (eds.), Biology of the Reptilia. New York, John Wiley e Sons.

Silva, N. J. 1993. The snakes from Samuel Hydroelectric Power Plant and Vinicity, Rondônia, Brazil. Herpelological Natural History 1: 37-86.

Silva, N. J. e J. W. Sites. 1995. Patterns of diversity of Neotropical squamate reptile species with emphasis on the Brazilian Amazon and conservation potential of indigenous reserves. Consevation Biology 9: 873-901.

Strüssmann, C. e I. Sazima. 1993. The assemblages of the Pantanal at Poconé Western Brazil: Faunal composition and ecology summary. Studies on Neotropical Fauna and Environment 28: 157-168.

Underwood, G. 1967. A Contribuition to the Classification of Snakes. London, British Museum of Natural History. 177 pp.

Vanzolini, P. E. 1948. Notas sobre os ofídios e lagartos da Cachoeira de Emas, no município de Pirassununga, Estado de São Paulo. Revista Brasileira de Zoologia 8: $377-400$.

Vanzolini, P. E. 1986. Addenda and corrigenda to the Catalogue of the Neotropical Squamata. Smithsonian Herpetological Information Service 70: 1-26.

Vanzolini, P. E., A. M. M. Ramos-Costa e L .J. Vitt. 1980. Répteis das Caatingas. Rio de Janeiro, Academia Brasileira de Ciências. 161 pp.

Vidal, N., S. G. Kindl, A. Wong e S. Blair-Hedges. 2000. Phylogenetic relationships of Xenodontine Snakes inferred from 12S and 16S ribosomal RNA sequences. Molecular Phylogenetics and Evolution 14: 389-402.

Vitt, L. J. e L. D. Vangilder. 1983. Ecology of a snake community in Northeastern Brazil. Amphibia-Reptilia 4: 273-296.

Wagler, J. 1824. Serpertum brasiliensium species novae. Monachii: Frac. Seraph. Hübschmann. vii +75 pp.

Wagler, J. 1830. Natürliches System der Amphibien, mit vorangehender Classification der Säugthiere und Vögel. München, J.G. Cotta. vi + 354p., 9 pl.

Yuki, R. N. e R. M. Santos. 1996. Snakes from Marajó and Mexiana islands, Pará State, Brazil. Boletim do $\mathrm{Mu}$ seu Paraense Emílio Goeldi, série Zoologia 12: 4153.

Zaher, H. 1999. Hemipenial morphology of the South 
American Xenodontine snakes, with a proposal for a monophiletic Xenodontinae and a repraisal of Colubroid hemipenes. Bulletin of the American Museum of Natural History 240: 1-168.
Zimmerman, B. L. e M. T. Rodrigues. 1990. Frogs, snakes and lizards of the INPA - WWF reserves near Manaus, Brazil. Pp. 426-454 in A. H. Gentry (ed.), Four Neotropical Rainforests. New Haven, Connecticut, Yale University Press.

\section{Apêndice}

Material Examinado

\section{Thamnodynastes chaquensis}

ARGENTINA: Chaco: San Fernando, Barranqueras (PMC 54), San Fernando, Antequera (PMC 101). BRASIL: Mato Grosso do Sul: Agachi (IB 41331, 42237, 42239, 42241, 42243, 42247, 42249, 42790, 42792, 42794, 42796, 42798, 42800, 42802, 42804, 42806, 42810, 42812); Aquidauna (IB 17225); Corumbá, Porto Esperança, Forte de Coimbra, (IB 10446); Corumbá (IB 18607, 18814, 18828, 32659, 33594, 42217, 42974, 42975); Guia Lopes [Guia Lopes da Laguna] (IB 13228); Miranda (IB 26506, 26547); Nabileque, Fazenda Andino, região Pantanal do Rio Paraguai (IB 37354, 37360); Passo do Lontra (IB 53710); Porto Murtinho (IB 40148). Mato Grosso: Cuiabá (IB 29339, 29340, 40848, 41356, 43811); Poconé (IB 54578). PARAGUAI: Assunção, Baía de Assunção (IB 10124-5).

\section{Thamnodynastes hypoconia}

ARGENTINA: Chaco: San Fernando, Antequera (PMC 141); San Juan, Puerto Viela (PMC 28). BRASIL: Bahia: Poções, Vila Bom Jesus (IB 28195). Espírito Santo: Araguaia (IB 17872). Goiás: Goiânia (IB 32780); Minaçu, UHE Serra de Mesa (IB 56728, 56729). Minas Gerais: Juiz de Fora (IB 34193); Perdizes (IB 4833). Mato Grosso: Arapuã (IB 14598); Rondópolis (IB 45536); Roncador (IB 12879). Mato Grosso do Sul: Nova Andradina (IB 41410); Taunay (IB 13279); Três Lagoas (IB 29351, 29353, 29354, 29442, 47610); UHE Sérgio Mota (247, 277, 307, 314, 344, 346, 347, 532, 533, 543, 558, IB 60093, 60098, 60104). Pernambuco: Petrolina (IB 48320); Petrolândia UHE Itaparica (IB 52134). Rio de Janeiro: Rio de Janeiro (IB 27930); Rio de Janeiro, Floresta da Tijuca (MNRJ 4813). Rio Grande do Sul: Canguçu (IB 52335); Caxias do Sul (IB 14317); Quinta (IB 16561); Rosário do Sul (IB 17634). Santa Catarina: Três Barras (IB 55751). São Paulo: Araçariguama (IB 56522, 56523); Assis (IB 26874); Bocaina (IB 13630); Brigadeiro Tobias (IB 12175); Caieiras (IB 12130); Campinas (IB 15586, 28677); Cotia (IB 37439, 37442); Descalvado (IB 44194); Franca (IB 26632); Ilha dos Três Estados, rio Paraná (IB 37997); Ilha Grande, rio Paraná, entre Rubinéia e Porto Itamarati (IB 37996); Itu (IB 28572, 29007, 45648, 45669, 45801); Jundiaí (IB 27316, 28624); Louveira (IB 28851); Mairiporã (CP 1206); Piedade (IB 58569); Porangaba (IB 8433); Porto Feliz (IB 54776); Presidente Prudente (IB25004); Santa fé do Sul (IB 16512); Santo Amaro (IB12304); São Carlos (IB 33366, 34394); São José dos Campos (IB 26890); São Paulo (IB 12395); Teodoro Sampaio (IB 51051); Tremembé, Central do Brasil (IB 10369); Fernandópolis, UHE Barra Vermelha (IB 41534, 41771, 41806, 41939, 42004); Ilha Solteira, UHE Ilha Solteira (IB 35261, 35262, 35285, 35298, 35764, 36246, 37014, 37657, 38291); Pereira Barreto, UHE Três irmãos, (IB 54020, IB 54042); Vinhedo (IB 58469).

\section{Thamnodynastes pallidus}

BRASIL: Acre: Tarauaca (IB 18533). Bahia: (IB 1847). GUIANA FRANCESA: (IB 13753).

\section{Thamnodynastes rutilus}

BRASIL: Distrito Federal: Brasília (IB 19183, 20584, 26761). Minas Gerais: Perdizes (IB 48332). São Paulo: Gália (IB 10337, holótipo); Lutécia (IB 58330); Marília (IB 17815); Presidente Epitácio, UHE Sérgio Motta, (IB 60258; Número de Campo 299); Ribeirão Preto (IB 52719); São Roque, fazenda São Joaquim (IB s/ $\mathrm{n}^{\circ}$ ); Ilha Solteira, UHE Ilha Solteira (IB 35230, 35934, 36221, 36311, 36491, 36736, 36820, 36900, 36901, 37213-4, 37723, 38314-6). Mato Grosso do Sul: UHE Sérgio Motta (IB 61267). Sem Procedência: IB 3469, parátipo. 


\section{Thamnodynastes strigatus}

BRASIL: Espírito Santo: Santa Teresa (IB 49051, 49052, 49054). Minas Gerais: Augusto Pestana, próximo a Passa Vinte (IB 9433); Baependi (IB 376); Camanducaia (IB 30017, 30287, 42342, 42399); Extrema (IB 57547); Machado (IB 57493); Munhoz (IB 56879); Sapucaia Mirim (IB 57383, 59889). Paraná: Cornélio Procópio (IB 9721); Curitiba (IB 49899, 49900); Ibaté (IB 29513); Mallet (IB 29592); Telêmaco Borba (IB 28662); Região do rio Iguaçu, entre Salto Osório e Faz. do Chopim (IB 40061). Rio Grande do Sul: Lagoa Vermelha (IB 49958, 49959); Pelotas (IB 41135); Porto Alegre (IB 42221, 42223). Santa Catarina: Canoinhas (IB 12697, 29644, 29645); Felipe Schmidt (IB 12715, 12717); Fragosos (IB 12906, 13590). Lança (IB 10881); Mafra (IB 29837, 29838, 49568); Piritiba-Piratuba (IB 29783, 29789). São Paulo: Atibaia (IB 11649, 29692); Caieiras (IB 57395); Cajobi [Monte Verde] (IB 20726); Campos do Jordão (IB 25342, 29436, 30238); Carapicuíba (CP 1245); Cotia (IB 758, 53836, CP 1154); Itapecerica da Serra (IB 52163); Jacareí (IB 29658); Joanópolis (IB 57409, CP 2466); São Roque, Mailasqui (IB 29621); Mogi das Cruzes (IB 57736); Ribeirão Pires (IB 28961); Santana de Parnaíba (IB 57567); São Bernardo do Campo (IB 13703); São José dos Campos (IB 54238); Taubaté (IB 29681); Teodoro Sampaio (IB 51052); Votorantim (IB 29558).

\section{Thamnodynastes sp. 1}

BRASIL: Bahia: Paulo Afonso (IB 44450). Espírito Santo: Afonso Cláudio (IB 49261, 49342-7); Araguaia (IB 18889); Castelo (IB 53721); Colatina (IB 29986, 49253); Guaçuí (IB 50610-11, 50613, 51069); Marilândia (IB 48929); Santa Teresa (IB 48763, 48764, 48789, 48791, 48812, 48886, 48907, 49048-9, 49053, 52466, 53817, 54297); São Domingos (IB 30220); São Gabriel da Palha (IB 49645, 50666). Minas Gerais: Coimbra (IB 21571); Dona Euzébia, Vila de Astório Dutra (IB 29989); Juiz de Fora (IB 37370, 45646, 45667, 45780, 45808); Mirantão (IB 54556); Taquaral (IB 29806). Mato Grosso do Sul: Corumbá (IB 17286). Pernambuco: Petrolândia (IB 52119). Paraná: Cruz Machado (IB 13300); Curitiba (IB 49896-8); Dorizon (IB 29796); Paulo Frontim (IB 21839); União da Vitória (IB 20839, 29595). Rio de Janeiro: Nova Friburgo (IB 12144). Rio Grande do Sul: Clara (IB 17784). Santa Catarina: Corupá (IB 11653); Fragosos (IB 12907, 13297); Mafra (IB 49569-72); São Joaquim (IB 45073); Valões (IB 17018); Videira (IB 19155). São Paulo: Capão Bonito (IB 29545); Iguape (IB 32728); Ilha Bela (IB 57092); Juquitiba (IB 32958); Visconde de Rio Claro [Rio Claro] (IB 12113). URUGUAI: Montevidéu (IB 55868). Topônimos não localizados: Joaquim Tavares (IB 16872); Sem Procedência (IB 41333).

\section{Thamnodynastes sp. 2}

BRASIL: Bahia: Barreiras (IB 50432, 50706); Brotas-Curaça (IB 43055); Guanambi (IB 50102, 50238, 50618, 54904, 54905, 54938); Juazeiro (IB 51718, 51834); Maracás (IB 58370); Paulo Afonso (IB 44444, 44446); Poções (IB 28143, 28190, 28191, 28192, 28194, 28195). Pernambuco: Caraíbas (IB 52350); Petrolândia, UHE Itaparica (IB 52113, 52114, 52115, 52116, 52117, 52118, 52127); Petrolina (IB 48317, 48318, 48319, 48320, 48321, 48322). Piauí: São Raimundo Nonato (IB 41291). Rio Grande do Norte: Lajes, antiga Itaretama (IB 30587); Natal (IB 44508).

\section{Thamnodynastes sp. 3}

BRASIL: Mato Grosso do Sul: Agachi (IB 42788). Pará: Monte Alegre (IB 40501, 40503, 40505, 40507, 40509, 40511-3, 40515, 40517, 40519, 40834, 40836, 40844, 40840, 40849, 42497, 42501, 42503).

\section{Thamnodynastes sp. 4}

BRASIL: Rio de Janeiro: Teresópolis (IB 41045); São Paulo: Areias (IB 31890); Guapiara (IB 33706); Itapecerica da Serra (IB 20694); Juquitiba IB (26561, IB 33702); Salesópolis, Estação Biológica de Boracéia (IB 18676); São Lourenço da Serra (IB 59545);

\section{Thamnodynastes sp. 5}

BRASIL: Pernambuco: Petrolândia, Usina Hidroelétrica Luiz Gonzaga no rio São Francisco (IB 53831; IB 53832). Bahia: Curaçá (IB 43052); Jaguararí, Mina Caraíba, nascente do Rio Curaçá (IB 26401; IB 28159,); Poções, Mina São Félix do Amianto, Vila Bom Jesus (IB 28160, IB 28161, IB 28162), Rodelas, Usina Hidroelétrica Luiz Gonzaga no rio São Francisco (IB 52088, IB 52120, IB 52121, IB 52122, IB 52124, IB 52125, IB 52126, IB 52128, IB 52129, IB 52130, IB 52131, IB 52132, IB 52133, IB 53735, IB 53764,). 